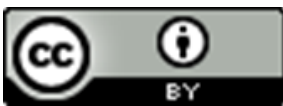

\title{
LEI E DISCRIMINAÇÃO NA PRODUÇÃO DA CIDADE SEGREGADA
}

\section{Lisandra Mara Silva ${ }^{1}$}

Resumo: Objetiva-se com esse artigo discutir aspectos da (re)produção da segregação racial da cidade de Belo Horizonte, Minas Gerais. De modo específico são problematizados os mecanismos discriminatórios presentes na legislação que, por meio da propriedade fundiária, corroboram com os processos de divisão da cidade. Como ponto de partida são apresentados dados da segregação racial em 2010. Como processo, são discutidos marcos jurídicos/temporais - do final do século XIX ao início do século $\mathrm{XX}$ - que ilustram um encadeamento de discriminações promovedoras da segregação pelo poder público. Como perspectiva são analisados regulamentos (leis, decretos e resoluções) onde a equidade de raça, gênero e classe é reivindicada de modo a subsidiar novas propostas de reparação em políticas urbanas e habitacionais.

Palavras-chave: segregação racial; propriedade fundiária; política urbana; política habitacional

\section{LAW AND DISCRIMINATION IN THE CITY SEGREGATED PRODUCTION}

Abstract: This article aims to discuss aspects of the (re)production of racial segregation in the city of Belo Horizonte, Minas Gerais. Specifically, the article problematizes the discriminatory mechanisms present in the legal system, which, through land ownership, corroborate the processes of division of the city. As a starting point, 2010 data on racial segregation are presented. As a process, legal/temporal frameworks are discussed - from the end of the 19th century to the beginning of the 20th century - that illustrate a chain of discrimination that promotes segregation by the public authorities. As a perspective, we analyse regulations (laws, decrees and resolutions) where the equity of race, gender and class is claimed in order to subsidize new proposals for redress in urban and housing policies.

Keywords: racial segregation; land ownership; urban policy; housing policy.

\section{LEY Y DISCRIMINACIÓN EN LA PRODUCCIÓN DE LA CIUDAD SEGREGADA}

\footnotetext{
${ }^{1}$ Arquiteta e Urbanista mestre em Arquitetura e Urbanismo pelo NPGAU/UFMG empregada pública da Companhia Urbanizadora e de Habitação de Belo Horizonte - Urbel. E-mail: lisandram@gmail.com ; ORCID: https://orcid.org/0000-0003-3664-234X
} 
Resumen: El objetivo de este artículo es discutir aspectos de la (re)producción de segregación racial en la ciudad de Belo Horizonte, Minas Gerais. Específicamente, los mecanismos discriminatorios presentes en el sistema legal se problematizan, lo que, a través de la propiedad de la tierra, corrobora los procesos de división de la ciudad. Como punto de partida, son presentados los datos sobre la segregación racial en 2010. Como proceso, se discuten los marcos legales/temporales, desde finales del siglo XIX hasta principios del siglo XX, que ilustran una cadena de discriminación que promueve la segregación por parte de las autoridades públicas. Como perspectiva, se analizan las regulaciones (leyes, decretos y resoluciones) donde se reclama la equidad de raza, género y clase para subsidiar nuevas propuestas de reparación en políticas urbanas y de vivienda.

Palabras clave: segregación racial; propiedad de la tierra; política urbana; política de viviend

\section{LOI ET DISCRIMINATION DANS LA PRODUCTION DE LA VILLE SÉGRÉGUÉE}

Resumé: L'objectif de cet article est de discuter certains aspects de la (re)production de la ségrégation raciale dans la ville de Belo Horizonte, Minas Gerais, Brésil. Les mécanismes discriminatoires présents dans l'aménagement juridique y sont plus particulièrement problématisés et, associés à la propriété foncière, confirment les processus de division de la ville. Des données de l'année 2010 concernant la ségrégation raciale ont servi de point de départ. Ce processus examine les cadres juridiques et temporels - allant de la fin du XIXe siècle au début du XXe siècle - qui illustrent l'enchaînement des discriminations ayant provoqué la ségrégation par les pouvoirs publics. La perspective choisie ici analyse les règlementations (lois, décrets et résolutions) qui introduisent le principe d'équité sans distinction de race, de sexe et de classe de façon à soutenir de nouvelles propositions de réparation dans les politiques urbaines et de logement.

Mots-clés: ségrégation raciale; propriété foncière; politique urbaine; politique du logement

\section{INTRODUÇÃO}

A segregação hierarquizada do espaço que caracteriza a cidade no âmbito do sistema capitalista é a materialização de práticas sociais de sua (re)produção (SANTOS, 1998). No processo dialético cidade-sociedade, observa-se que as dinâmicas de poder que constituem a hierarquização do espaço se perpetuam de modo a garantir a manutenção de lógicas excludentes funcionais à reprodução do capital. Como parte desse arsenal, a ideia de raça, historicamente forjada, é utilizada para garantir a superiorização ou inferiorização de pessoas, assim como de suas práticas e territórios. 
Trata-se, nessa discussão, de um recorte do processo dialético de produção da cidade onde o racismo a produz e é por ela produzido.

Busca-se realizar uma leitura do processo de segregação racial a partir de contribuições de dois instrumentos de análise: a história como práxis - a compreensão do pensamento, da ação das pessoas e do significado das coisas a partir das relações sociais e suas diferenças ao longo do tempo - como sugere Milton Santos (1998), e a interseccionalidade - a compreensão das dimensões de gênero, raça e classe na experiência social - a partir da proposta de Kimberlé Crenshaw (1991).

Como ponto de partida são apresentados dados da segregação racial da cidade de Belo Horizonte. Em seguida, são analisadas leis nacionais e locais, do século XIX à década de 1930, de modo a demonstrar mecanismos discriminatórios que corroboram com o processo de construção, pelo poder público, de um núcleo embranquecido da cidade (que se aproxima do atual limite administrativo da Regional Centro-Sul). O eixo condutor da análise é a propriedade fundiária, principal símbolo do sistema capitalista, que se espalha no globo com a modernidade colonizadora tornando-se instrumento de poder de distinção social, política e econômica nas dinâmicas de produção da cidade.

Ao final, como perspectiva de atuação, são abordados mecanismos reparadores presentes na legislação - como a lei do Programa Municipal de Regularização de Favelas (Profavela) de 1985, a Resolução LII do Conselho Municipal de Habitação de 2018 e a lei do Plano Diretor de 2019 - de modo a somar subsídios para a articulação entre as políticas Urbana, Habitacional e de Promoção da Igualdade Racial de Belo Horizonte na construção de uma agenda de reparações.

\section{PONTO DE PARTIDA: DADOS DA SEGREGAÇÃO RACIAL}

Belo Horizonte é uma cidade majoritariamente negra: 51,94\% de sua população é composta por autodeclarados pretos e pardos (SILVA, 2018, p.183). ${ }^{2}$ A denominação territórios negros utilizada nessa discussão para se referir a favelas, loteamentos irregulares e conjuntos habitacionais, para além dos tradicionais quilombos e terreiros, se dá a partir dos dados que evidenciam a negritude, seja pela sobrerrepresentação de

2 São apresentados alguns resultados da pesquisa de mestrado realizado pela autora concluída em 2018, realizada no Núcleo de Pós-graduação em Arquitetura e Urbanismo da Universidade Federal de Minas Gerais (NPGAU/UFMG). Estudo realizado com o apoio da Companhia Urbanizadora e de Habitação de Belo Horizonte - Urbel onde é exercida atuação profissional desde 2013. 
população negra, seja pela presença de tradição cultural negra. ${ }^{3}$ Já núcleos embranquecidos é uma denominação que resulta da interpretação da espacialização da cor de pele na cidade e diz do processo de produção (branqueamento) desses territórios. Com as designações não pretende-se homogeneizá-los: territórios devem ser considerados em suas especificidades.

A leitura de cidade realizada a partir dos núcleos embranquecidos forjou uma dicotomia urbana funcional à hierarquização socioespacial, onde o centro é referenciado como cidade e a periferia, o outro lugar, suburbano, subnormal, irregular, informal e ilegal. Dicotomia funcional à reprodução dos discursos legitimadores dos lugares do racismo que, como problematizam Reinaldo José de Oliveira e Regina Marques Souza Oliveira (2015) na discussão sobre as Origens da Segregação Racial no Brasil, são dinamizados no corpo da cidade (OLIVEIRA E SOUZA OLIVEIRA, 2015). Estigmas atribuídos às pessoas, assim como às suas práticas culturais, econômicas, políticas e na relação com a terra - "o estigma do invasor na produção do espaço urbano" - na manutenção das estruturas da sociedade (SILVA E PEREIRA, 2018, p. 29).

Corroborando com as características da segregação racial apresentadas por estudos sobre as metrópoles brasileiras como Rio de Janeiro, Salvador e São Paulo (CAMPOS, 2017; GARCIA, 2009; OLIVEIRA, 2013), em BH, uma maior quantidade de população branca habita lugares da cidade com maior oferta de infraestrutura, trabalho e emprego, serviços públicos e comunitários (estudo, saúde, lazer) (Silva, 2018, p.183-185). Questões como o menor tempo de deslocamento para o desenvolvimento de atividades do cotidiano assim como um maior acesso a condições urbanas para a garantia da saúde e da reprodução da vida alteram significativamente a experiência de cidade por parte da população branca e não branca.

Observa-se na Tabela 1 que os maiores Índices de Bem Estar Urbano (IBEU) e as maiores rendas médias por pessoa são indicados nas regionais Pampulha e Centrosul. A segunda se destaca pela renda média por pessoa com mais de 10 anos de 6,37 salários mínimos (s.m.), significativamente mais alta que as demais que variam de 3,15 a 1,33 s.m. (Silva, 2018, p.190).

3 A negritude é definida por Sartre como a negação da negação do homem negro, instrumento de combate à dominação colonial, de significado político e revolucionário (MUNANGA, 1986). 
Tabela 1 - Distribuição \% das pessoas negras, IBEU e renda média por pessoa nas regionais de $\mathrm{BH}$

\begin{tabular}{|c|c|c|c|c|c|c|c|c|c|}
\hline \multirow[b]{2}{*}{ Regional } & \multirow[b]{2}{*}{$\begin{array}{c}\text { Mulheres } \\
\text { negras }\end{array}$} & \multirow[b]{2}{*}{$\begin{array}{c}\text { Homens } \\
\text { negros }\end{array}$} & \multicolumn{6}{|c|}{ IBEU } & \multirow[b]{2}{*}{$\begin{array}{c}\text { Renda média / } \\
\text { pessoa } \\
\text { com + de 10 } \\
\text { anos (em } \\
\text { salários } \\
\text { mínimos) }\end{array}$} \\
\hline & & & 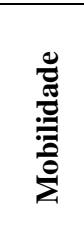 & 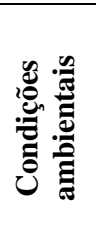 & & 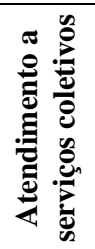 & 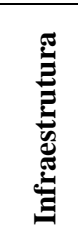 & 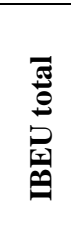 & \\
\hline BARREIRO & $7,33 \%$ & $6,62 \%$ & $\underline{0,63}$ & 0,89 & 0,84 & 0,95 & 0,69 & $\underline{0,80}$ & $\underline{1,34}$ \\
\hline CENTRO-SUL & $3,37 \%$ & $2,61 \%$ & 0,91 & 0,96 & 0,91 & 0,99 & 0,84 & 0,92 & 6,37 \\
\hline LESTE & $5,72 \%$ & $4,76 \%$ & 0,84 & 0,90 & 0,84 & 0,97 & 0,72 & 0,85 & 2,39 \\
\hline NORTE & $5,97 \%$ & $5,24 \%$ & 0,70 & 0,92 & 0,84 & 0,94 & 0,72 & 0,82 & 1,39 \\
\hline NORDESTE & 7,13 & $6,27 \%$ & 0,78 & 0,93 & 0,86 & 0,97 & 0,74 & 0,86 & 2,10 \\
\hline NOROESTE & 7,51 & $6,33 \%$ & 0,81 & 0,91 & 0,87 & 0,99 & 0,73 & 0,86 & 2,13 \\
\hline OESTE & 5,75 & $4,97 \%$ & 0,86 & 0,89 & 0,86 & 0,98 & 0,74 & 0,86 & 2,73 \\
\hline PAMPULHA & 3,64 & $3,19 \%$ & $\mathbf{0 , 7 8}$ & 0,95 & $\mathbf{0 , 9 0}$ & 0,97 & 0,76 & $\mathbf{0 , 8 7}$ & 3,15 \\
\hline VENDA NOVA & 7,18 & $6,42 \%$ & $\underline{0,58}$ & 0,90 & 0,86 & 0,96 & 0,70 & $\underline{0,80}$ & $\underline{1,33}$ \\
\hline BH & \multicolumn{2}{|c|}{$100,00 \%$} & & & & & & $\mathbf{0 , 8 5}$ & \\
\hline
\end{tabular}

Fonte: Elaborado pela autora a partir de dados do IBGE 2010, IBEU 2017 e Silva 2018

Observa-se que as regionais Centro-sul e Pampulha se constituem como núcleos embranquecidos. $\mathrm{O}$ número de pessoas negras tende a aumentar proporcionalmente ao afastamento desses núcleos. Na Figura 1 observam-se ilhas de concentração de população negra na regional Centro-Sul, territórios negros que equivalem às grandes favelas da Serra, ao leste, do Santa Lúcia, ao sul, do Morro das Pedras, ao oeste, e menores como a Monte São José (arredores do bairro Cidade Jardim) e a Acaba Mundo (arredores do bairro Sion). A Zona Urbana do projeto da Comissão Construtora para a Cidade de Minas equivale ao polígono da atual Avenida do Contorno. ${ }^{4}$

4 O mapa (Figura 1) e as tabelas foram elaborados a partir de dados do Censo Demográfico do Instituto Brasileiro de Geografia e Estatística (IBGE) realizado entre $1^{\circ}$ de agosto e 30 de outubro de 2010. No universo de pesquisa sobre as características da pessoa, a cor ou raça foi autodeclarada pelo entrevistado a partir de cinco opções: branca, preta, amarela (oriental), parda e indígena. A soma dos pretos e pardos como representantes da população negra é uma categoria concebida a partir de questões políticas e sociais (Oliveira, 2013; Campos, 2007). Para espacialização dos dados foram adotados critérios semelhantes aos adotados na elaboração do mapa da População preta e parda do município de São Paulo pela Secretaria Municipal de Desenvolvimento Urbano da Cidade de São Paulo (SMDU), em 2016. 
Figura 1 - Distribuição da população preta e parda no polígono determinado pela

Avenida do Contorno e adjacências

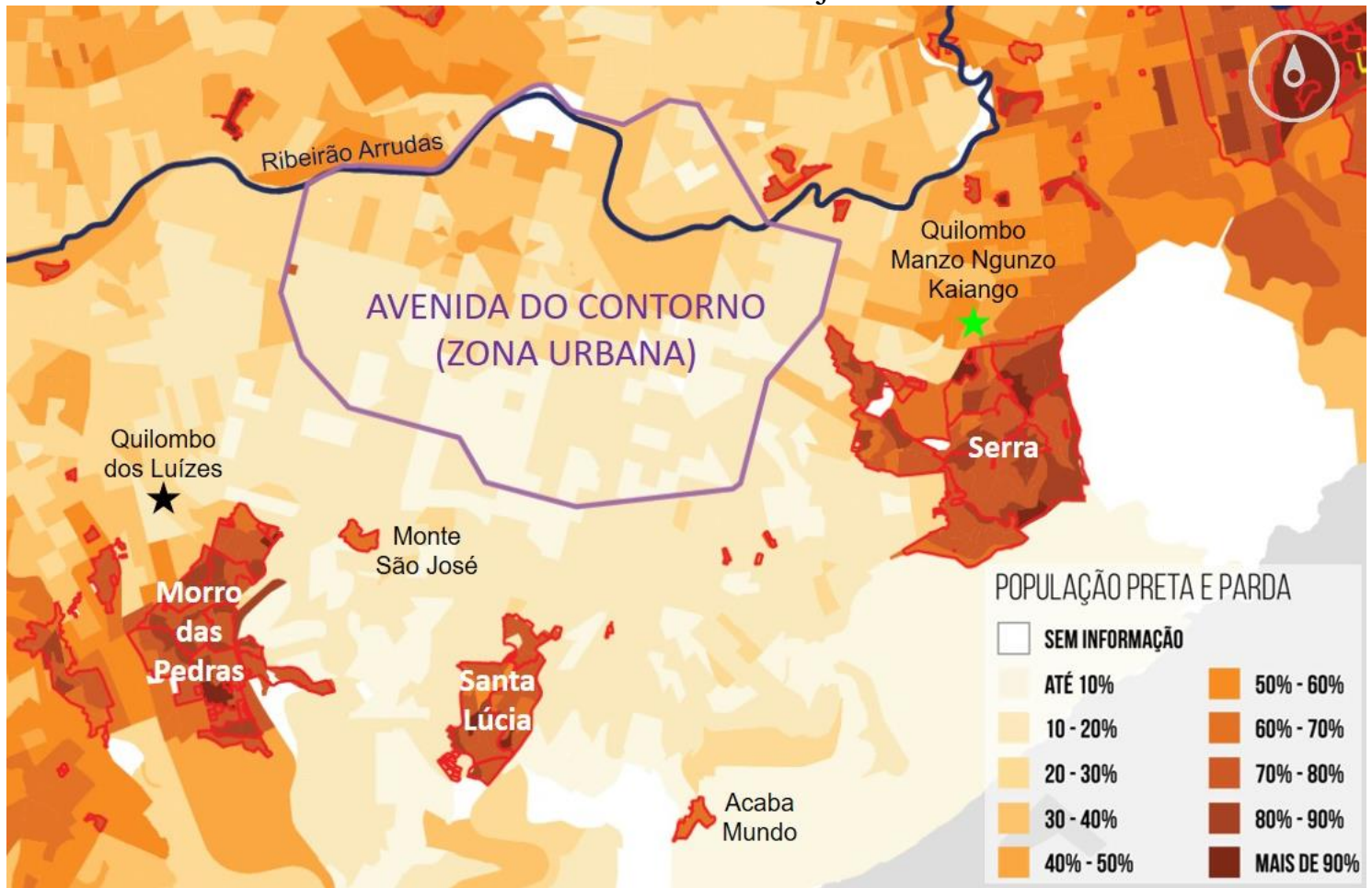

Fonte: Elaborado pela autora a partir de dados do IBGE 2010

Tabela 2 - \% de pessoas negras em relação ao total de pessoas: ZEIS-1, ZEIS-3 e residenciais do PMCMV

\begin{tabular}{lccc}
\hline \multicolumn{1}{c}{ Local } & $\begin{array}{c}\text { Mulheres } \\
\text { negras }\end{array}$ & $\begin{array}{c}\text { Homens } \\
\text { negros }\end{array}$ & $\begin{array}{c}\text { Pessoas } \\
\text { negras }\end{array}$ \\
\hline VILAS E FAVELAS (ZEIS-1) & $38,22 \%$ & $33,85 \%$ & $72,07 \%$ \\
\hline CONJUNTOS PRÉ-1993(ZEIS-3) & $42,16 \%$ & $37,33 \%$ & $79,49 \%$ \\
\hline RESIDENCIAIS DO PMCMV FAIXA 1 - FASE 2 (AEIS-1) & $46,99 \%$ & $25,67 \%$ & $72,66 \%$ \\
\hline
\end{tabular}

Fonte: Elaborado pela autora a partir de dados do IBGE 2010, Urbel 2017 e Silva 2018

Enquanto pouco mais da metade da população de BH se autodeclara negra, aproximadamente três quartos dos moradores de favelas, conjuntos habitacionais produzidos pelo poder público (ZEIS-1 e ZEIS-3) e residenciais do Programa Minha Casa Minha Vida (AEIS-1) são negros, sobretudo mulheres (Tabela 02). ${ }^{5} \mathrm{Se}$

5 Os dados de Vilas e favelas e Conjuntos Pré-1993 (conjuntos Habitacionais construídos em período anterior à criação da Política Municipal de Habitação no ano de 1993), apresentados na Tabela 2 têm como origem o Censo IBGE 2010. Os dados por cor de pele dos moradores dos residenciais do Programa Minha Casa Minha Vida (PMCMV) construídos na segunda fase do programa, têm como origem cadastros realizados pela Urbel entre os anos de 2013 e 2016, sendo utilizado método de pesquisa semelhante ao do Censo Demográfico 2010 do IBGE. No Plano Diretor de BH são ZEIS as Zonas Especiais de Interesse Social e AEIS as Áreas Especiais de Interesse Social. A pesquisa incluiu apenas as 
considerados os extremos, enquanto a mulher negra trava a luta pela sobrevivência, o homem branco luta pelo enriquecimento. Trata-se dos resultados de processos históricos-sociais onde as dinâmicas colonialistas, patriarcais e capitalistas são reproduzidas inclusive por meio de mecanismos discriminatórios presentes na legislação, o que pretende-se demonstrar nessa reflexão.

São inerentes à lei as contradições entre discurso e prática ou intenção e implementação. Interessa a essa discussão, inicialmente, menos a implementação das determinações legais e mais a sua compreensão como discurso que diz das ideias e das práticas sociais em determinado momento histórico e que necessariamente produzem território.

\section{PROCESSOS: MECANISMOS DISCRIMINATÓRIOS}

O processo de segregação racial no Brasil não se deu de forma institucionalizada ou legalizada, aos moldes dos processos ocorridos na África do Sul, nos Estados Unidos ou na Europa com a criação de guetos judeus no período de ascensão do nazismo (GARCIA, 2009; OLIVEIRA, 2013). Defende-se que a segregação racial brasileira é resultado do movimento de mecanismos discriminatórios. Compartilha-se com Luciana Jaccoud (2008, p.45) o entendimento que a desigualdade racial, para além de simples acúmulos históricos da pobreza e da falta de acesso à educação e à cidade é reflexo desses mecanismos diferenciadores. Na discussão que segue busca-se ilustrar alguns desses mecanismos presentes na legislação e que, de modo específico, estruturam as diferentes condições de acesso à terra pela população branca e não branca. Diferenciações operadas por meio da propriedade fundiária desde a Lei de Terras de 1850.

O processo de alteração do significado de terra e trabalho necessário à expansão global do sistema capitalista resultou no Brasil, ao longo do século XIX, em marcos jurídicos significativos como a Lei de Terras, as várias proibições ao tráfico negreiro e a Abolição da Escravidão (COSTA, 2010; ROLNIK, 1997). A Lei nº 601 de 1850 reduziu a possibilidade de aquisição de terras devolutas ao título de compra e autorizou o governo a promover a colonização estrangeira (CAMPOS, 2007; JACCOUD, 2008;

áreas classificadas no zoneamento municipal como AEIS-1 onde estão localizados residenciais do PMCMV. 
MOURA, 1994). Como analisa Raquel Rolnik (1997), ao transformá-la em estatuto jurídico, a lei possibilita a utilização da terra como garantia em hipotecas para a contratação de empréstimos bancários, utilizados pelas elites como estratégia para ampliação dos cultivos.

Ainda que a Lei de Terras anteceda a abolição em 48 anos, aponta Clovis Moura (1994) que a Lei Eusébio de Queiroz (1850), promulgada poucos dias antes, condenaria ao fim o regime escravista ao proibir o tráfico negreiro em período de crescimento negativo de escravizados. Compartilha-se com Clovis Moura (1994) a compreensão que condicionar o acesso à terra ao capital econômico da população afastou do poder público o dever social de doar aos ex-cativos parcelas de terras como ação indenizatória do processo abolicionista. De modo concomitante, possibilitou que as maiores fortunas do país se formassem e perpetuassem a partir da concentração da propriedade fundiária, como aponta Andrelino Campos (2007).

Nesse contexto, quando a terra substituiu os escravizados na composição da riqueza, ou seja, as elites brasileiras adotaram o projeto de poder econômico e político de substituição da propriedade de pessoas escravizadas pela propriedade fundiária, é forjada a ilegalidade compulsória da ocupação da terra. Ilegalidade reservada à população excluída das dinâmicas sociais do acesso à propriedade fundiária, pessoas escravizadas, libertas e nascidas livres, sobretudo não brancas.

Três anos antes da abolição da escravidão, a Lei Saraiva-Cotegipe (Lei n ${ }^{\circ} 3.270$ de 1885), buscou concretizar a proposta da extinção gradativa do cativo. De modo a indenizar os proprietários, regulamentava a realização da matricula de escravizados e a fixação de valor por faixa etária. ${ }^{6}$ Aos indivíduos do sexo feminino seria aplicado um abatimento de $25 \%$ do valor, o que evidencia discriminações de gênero e a intenção de facilitar a compra da alforria feminina.

Art. $1^{\circ}$ Proceder-se-ha em todo o Imperio a nova matricula dos escravos (...) $\S 4^{\circ} \mathrm{O}$ valor dos individuos do sexo feminino se regulará do mesmo modo, fazendo-se, porém, o abatimento de $25 \%$ sobre os preços acima estabelecidos.(...)

Art $3^{\circ}$ Os escravos inscriptos na matricula serão libertados mediante indemnização de seu valor pelo fundo de emancipação ou por qualquer outra fórma legal. (...)

6 A matrícula do escravizado já era prevista na Lei no 2.040 de 1871, Lei do Ventre-Livre, que também criou o Fundo e Emancipação com o objetivo de promover a alforria de forma gradativa. 
$\S 14$ - É domicílio obrigado por tempo de cinco anos, contados da data da libertação do liberto pelo Fundo de Emancipação, o município onde tiver sido alforriado, exceto o das capitais.

$\S 15-\mathrm{O}$ que se ausentar de seu domicílio será considerado vagabundo e apreendido pela polícia para ser empregado em trabalhos públicos ou colônias agrícolas. (...)

Observa-se na lei a intenção de controle da localização de moradia da população liberta distante das capitais, como problematiza Carlos Vainer (2000, p.59) na reflexão "Do Corpo marcado ao território demarcado". Compartilha-se com o autor a compreensão que a exceção feita às capitais como domicílio obrigatório do liberto vem de encontro ao interesse em favorecer todo e qualquer deslocamento da população negra da cidade para os campos, o que corroboraria com o projeto de embranquecimento das cidades.

Se em âmbito nacional a propriedade fundiária é reconhecida como estruturadora da concentração e da valorização de terras, assim como determinante da regularidade do desenho urbano (Rolnik, 1997), o mesmo observa-se em Belo Horizonte. Acrescenta-se, o papel da propriedade fundiária como instrumento de embranquecimento do território criado para ser signo da república brasileira, o que procura-se demonstrar ao longo dessa discussão.

\section{CONTROLAR O ACESSO À TERRA NA NOVA CAPITAL: DÉCADA DE} 1890

No século XVIII, o dinamismo da economia motivado pelo ciclo do Ouro e do Diamante provocou um acelerado crescimento demográfico na Capitania de Minas Gerais. Como problematiza o historiador Tarcísio Botelho (2007, p.21), sabe-se que a Capitania chegou a concentrar vinte por cento da população brasileira no século XVIII, e no século XIX “deteve o maior plantel escravista do Brasil”, mão de obra significativa que possibilitou uma menor dependência da imigração estrangeira na transição para o trabalho livre, em relação a São Paulo, por exemplo.

Conforme dados levantados e compilados pela historiadora Josemeire Alves Pereira (2015a, 2015b, 2018), o primeiro recenseamento realizado em 1776 na Capitania de Minas Gerais indica $83 \%$ de população mestiça e preta. Percentual semelhante observa-se no Arraial do Curral Del Rey, localidade escolhida para a 
construção da capital Belo Horizonte em substituição a Ouro Preto. Em 1816, viviam no local 18.314 pessoas, dentre as quais $82 \%$ negras ( $47 \%$ livres e $35 \%$ escravizadas); e em 1840, registros paroquiais do arraial indicam um total de 2.241 pessoas, sendo $83 \%$ negras (61\% livres e 22\% escravizadas) (SILVA E PEREIRA, 2018).

Uma cidade da república, moderna, do trabalho livre e branca era o projeto da elite mineira. Uma cidade em contraponto à então capital Ouro Preto, negra não apenas no nome, mas na produção do território: no conjunto urbano, nos sistemas construtivos tradicionais de habitações, nos templos religiosos, muros, chafarizes, pontes, e nas estruturas da mineração, como indicam Rodrigo Nogueira e Flora Passos (2017, p.104) no artigo "Arquitetura tradicional de Ouro Preto: preciosa por ser negra".

Também negro, o Arraial do Curral Del Rey foi violentamente alterado pelo empreendimento da nova capital, projetada à luz dos padrões urbanísticos europeus do fazer cidade. É adotado um projeto de cidade que, para responder à necessidade de demarcação precisa da propriedade fundiária, altera a lógica de produção do espaço (Rolnik, 1997). Como analisa Raquel Rolnik (1997, p.25), "aparece a figura do loteamento ou arruamento, o desenho das ruas e lotes prévios ao próprio ato de construir". A precisão da demarcação determina o desenho e desconsidera ou relega ao segundo plano o que foi produzido pela sociedade, as dinâmicas de vida preexistentes e as características ambientais como topografia e hidrografia. 
Figura 2 - Planta cadastral do Curral Del Rey sobreposta à planta da Nova Capital

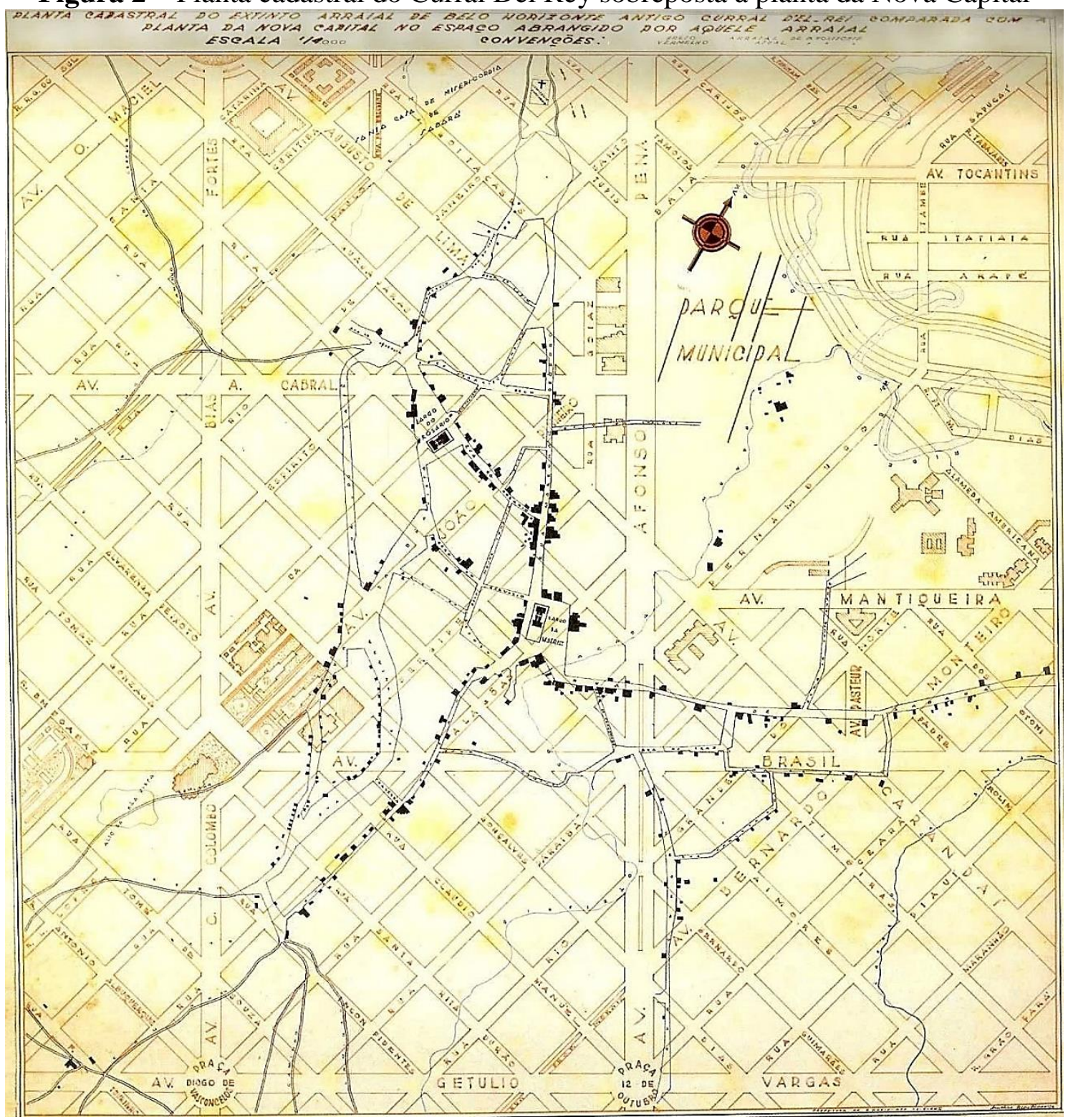

Fonte: Arquivo Público Mineiro, acervo da Comissão Construtora da Nova Capital, s.d.

Um modelo de intervenção urbana patriarcal, com decisões de várias naturezas, inclusive as desapropriações, centradas exclusivamente na figura do engenheiro chefe da Comissão Construtora, o que observa-se nas determinações do Decreto Estadual $n^{\circ}$ 680 de 1894, que organiza a Comissão Construtora da Nova Capital:

Art. $2^{\circ}$ - Os trabalhos afetos à Comissão abrangerão: (...)

$\S 5^{\circ}$ - A desapropriação, amigável ou judicial, dos terrenos que tiverem de ser ocupados pela nova Capital, de acordo com o projeto geral que for aprovado e, bem assim, dos prédios e benfeitorias que tiverem de ser demolidos e inutilizadas, observadas as disposições legais. (...)

Art. 11 - Será da exclusiva competência do engenheiro chefe: (...) 
$\S 4^{\circ}$ - A desapropriação, amigável ou judicial, dos terrenos, prédios e benfeitorias, que for necessária para a realização do projeto geral da nova Capital.

Por meio da desapropriação de terrenos, prédios e benfeitorias, a propriedade fundiária mantém-se como mecanismo de distinção das formas de acesso à terra e à moradia. Proprietário das terras necessárias à concretização do plano, o poder público, por meio da Comissão Construtora, tem o poder de exercer pleno controle do acesso à propriedade fundiária. Prática que, segundo Somarriba, Valadares e Afonso (1984, p.30) "permitiu a concentração e acumulação da propriedade privada do solo, com consequente especulação imobiliária". Um projeto de enriquecimento de um grupo seleto.

A antiga população moradora do Curral Del Rey, constituída majoritariamente por mulheres negras livres e libertas, era indesejada na nova capital (AGUIAR, 2006, SILVA E PEREIRA, 2018). Após as desapropriações, os valores pagos "resultariam baixos e insuficientes para assegurar que os curralenses retornassem como proprietários em condições semelhantes às que desfrutavam até serem expropriados" (AGUIAR, 2006, p.158). Para a efetivação do projeto de cidade, a Constituição Estadual é alterada pela Lei Adicional no 3 de 1893 onde são propostas diferenciações no acesso à terra e à moradia:

Art. $2^{\circ}$ - Fica o governo autorizado: (...)

$6^{\circ}$ - A estipular, nas concessões que fizer, condições para promover construções de casas destinadas aos empregados públicos de que trata $\mathrm{o} \mathrm{n}^{\circ} 7$ do art. $2^{\circ}$, de modo a facilitar-lhes o pagamento em prestações que poderão ser deduzidas de seus vencimentos, se o requerem.

Igualmente promoverá a construção de casas em condições higiênicas e de aluguel barato para operários.

$7^{\circ}$ - A conceder a título gratuito, aos atuais funcionários estaduais que por lei têm residência obrigatória na Capital, e que o requererem, um lote de terreno para construção de casa ou chácara, antes de serem postos em hasta pública, assim como transporte e ajuda de custo.

$8^{\circ}$ - A conceder a título gratuito, a cada um dos atuais proprietários de casas em Ouro Preto, situadas no perímetro estabelecido para cobrança do imposto predial no exercício de 1900, um lote de terreno para edificação.

Em síntese, a escala hierárquica do acesso à terra em Belo Horizonte a partir de 1893 seria: i) Lote a título gratuito aos proprietários de Ouro Preto contribuintes do imposto predial em 1900 e aos funcionários estaduais com residência obrigatória na 
capital. ii) Casas em pagamento facilitado por prestações aos empregados públicos; iii) Casas em condições higiênicas e de aluguel barato aos operários.

Os operários que constroem a capital no final do século XIX, assim como ao longo do século XX, são sobretudo negros: ex-curralenses (que a despeito do previsto em projeto permaneceram no arraial, em favelas, vilas operárias e localidades distantes da Zona Urbana) e migrantes, principalmente mineiros e brasileiros (BOTELHO, 2007; Silva \& Pereira, 2018). Aos operários é prevista como moradia uma hospedaria provisória implantada pela Comissão Construtora para abrigar 200 pessoas, que resultou rapidamente "insuficiente para acolher a todos que chegavam, e provocou o surgimento de cafuas e barracos por todos os lados" (GUIMARÃES,1992, p.12).

Forma-se com o início do empreendimento a favela do Alto da Estação (na atual região do bairro Floresta) e um agrupamento de cafuas nos arredores do Córrego do Leitão (na atual região do Barro Preto), reunindo cerca de 3.000 pessoas já em 1895 (GUIMARÃES, 1992; LIMA, 2009). ${ }^{7}$ As terras onde inicialmente se instalaram cafuas e barracos, embora ocupadas por famílias de operários conforme a conveniência do empreendimento e sob o conhecimento do poder público, não eram passíveis de negociação, dando continuidade ao modelo de ocupação compulsoriamente ilegal. No ano de inauguração, Belo Horizonte possuía concentrações de cafuas e organização de base local para a reivindicação por serviços de consumo coletivo (Somarriba, Valadares e Afonso, 1984); modos de morar e lutas urbanas que se diversificaram com o tempo mas não deixaram de caracterizar a história da população negra ao longo do século XX: a luta pela sobrevivência.

\section{NEGOCIAR TERRAS COM OPERÁRIOS: DÉCADAS DE 1900 A 1930}

O poder público proprietário intervém no acesso à terra conforme seus interesses; controla a provisoriedade dos territórios negros e a ilegalidade de sua ocupação. Sob o controle do poder público, as famílias de operários constituem moradia em favelas, em áreas e vilas operárias; territórios negros que passam a ser continuamente removidos sendo as famílias reassentadas conforme as decisões dos

7 Testemunha da tecnologia construtiva africana em diáspora, a cafua é termo encontrado nos documentos administrativos da cidade nas primeiras décadas do século XX. Trata-se da casa de negros também denominada na literatura como mocambo; arquitetura de terra construída em paredes de pau a pique e cobertura em folhas de palmeira (SILVA E PEREIRA, 2018). 
governos (GUIMARÃES, 1991). Em 1897, com a inauguração da cidade, desfaz-se a Comissão Construtora e estabelece-se a Prefeitura Municipal de Belo Horizonte (órgão subordinado à Presidência do Estado) (LIMA, 2009).

\section{LOTES GRATUITOS A TÍTULO PROVISÓRIO NA ZONA URBANA}

Em 1902, no mesmo ano em que a possibilidade de aquisição definitiva dos terrenos pelos operários por meio da compra foi inaugurada pelo Decreto Estadual 1.516 (que regulou a concessão de terrenos à indústrias, associações e a venda a particulares) parte das famílias removidas da favela do Alto da Estação e dos arredores do Córrego do Leitão foram reassentadas pelo poder público na área operária do Barro Preto, criada na oitava secção urbana (LIMA, 2009). Em 1909 chega a ser prevista, por força da Lei $\mathrm{n}^{\circ} 33$, a cessão gratuita de lotes a operários por meio de títulos provisórios até a construção das casas (LIMA, 2009):

Art. $1^{\circ}$ - Fica o Prefeito auctorizado a deslocar para a "area operaria" a oitava secção urbana, conhecida por "Barro Preto", ou designar outro local da cidade para "area operaria" e nella conceder a todos os operarios que o requererem um lote de terreno gratuitamente.

Paragrapho unico - Para os fins deste artigo, consideram-se operarios exclusivamente aquelles individuos que tiverem meios de subsistencia de trabalhos manuaes.

Art. $4^{\circ}$ - Os lotes serão concedidos a titulos provisorios, até que sejam nelles costruidas casas. Depois de construidas e examinadas pela Prefeitura, serão então concedidos aos concessionarios titulos definitivos dos lotes.

Moradoras da área operária do Barro Preto por incentivo do poder público, famílias de operários serão novamente removidas da Zona Urbana. Em relatório do ano de 1918, o prefeito Affonso Vaz de Melo (1918) destaca a necessidade da prefeitura remover "grande número de operários instalados provisoriamente na área operária Barro Preto - os quaes, à vista das disposições da Lei no 138, de 16 de outubro de 1917, não poderão mais conseguir domínio definitivo dos lotes que ocuparem" (BELO HORIZONTE, 1918, p.14 apud LIMA, 2009, p. 56).

Desse modo, o poder público possibilitou a famílias operárias o acesso à propriedade fundiária de terras localizadas na Zona Urbana por 15 anos, de 1902 a 1917. Após esse período, grande número de famílias seriam removidas e eliminada a área operária do Barro Preto. 


\section{LOTES ADQUIRIDOS EM HASTA PÚBLICA NA ZONA SUBURBANA OU}

\section{COLONIAL}

A outra parte das famílias removidas das favelas do Alto da Estação e dos arredores do Córrego do Leitão, não reassentadas na área operária do Barro Preto, passam a constituir as favelas Pedreira Prado Lopes e da Barroca entre 1909 e 1914 (GUIMARÃES, 1992). A favela da Barroca, iniciada em 1902 também na região do Barro Preto existe por aproximadamente 40 anos na Zona Urbana. Com as ações de remoção, parte dos moradores deslocam-se para outras áreas (como a favela dos Marmiteiros e o Morro do Querosene) e parte volta a constitui-la continuamente ao longo da atual Av. Olegário Maciel. Em 1942, a favela da Barroca encontrava-se onde hoje localiza-se a Praça da Assembleia (GUIMARÃES, 1992).

A existência de cafuas e barracões levou o prefeito Flávio Fernandes dos Santos a declarar em 1922 a urgência da criação de vilas operárias diante da impotência do poder público no impedimento da ocupação de seus terrenos (Silva, 2013). A negociação de terras públicas com operários é então retomada com a Lei no 309 de 1926:

Art. $1^{\circ}$ - Os lotes pertencentes á Prefeitura e que possam ser alienados, sómente o serão, daqui por deante, em hasta publica, de conformidade com esta lei. (...) Art. 12 - O Prefeito creará na zona suburbana ou colonial, em pontos convenientes, uma ou varias villas proletarias, exclusivamente destinadas á localização de operarios. (...)

Art. 16 - Só poderá concorrer a essas praças o operario que não possuir lote e não tiver gosado de favores das leis anteriores para a acquisição de um e que, além disso, prove:

a) que é casado ou tem encargo de familia;

b) que tem economia seperada;

c) que é operario,

d) que tem bom comportamento.

As vilas operárias são previstas apenas nas zonas suburbana e colonial. A intenção de que as famílias fossem mantidas fora da Zona Urbana da capital, associada ao bom comportamento que deveriam provar, indicam possíveis intenções de controle social do proletariado além do afastamento da população negra da Zona Urbana - que atualmente equivale ao interior do polígono da Avenida do Contorno. 


\section{0}

LOTES A TÍTULO DE AFORAMENTO EM VILAS EXTERNAS À ZONA

\section{URBANA}

Em 1928, a Lei Municipal no 335 inaugura a concessão de lotes a operários por enfiteuse. No mesmo ano é criada, após negociações com famílias de operários, a "Villa Proletária Concórdia” (Lima, 2007, p.157). Segundo Júnia Ferrari Lima (2007), trata-se da primeira vila operária oficialmente criada na capital. Com o andamento do empreendimento na Zona Urbana e os trabalhos de canalização do córrego da Barroca, a população provisoriamente localizada na favela da Barroca foi paulatinamente transferida para a Vila Concórdia, localizada na zona suburbana, onde os lotes foram concedidos às famílias operárias por meio de títulos de aforamento. ${ }^{8}$

Figura 3 - Canalização do Córrego da Barroca (Rua Mato Grosso) em 1928

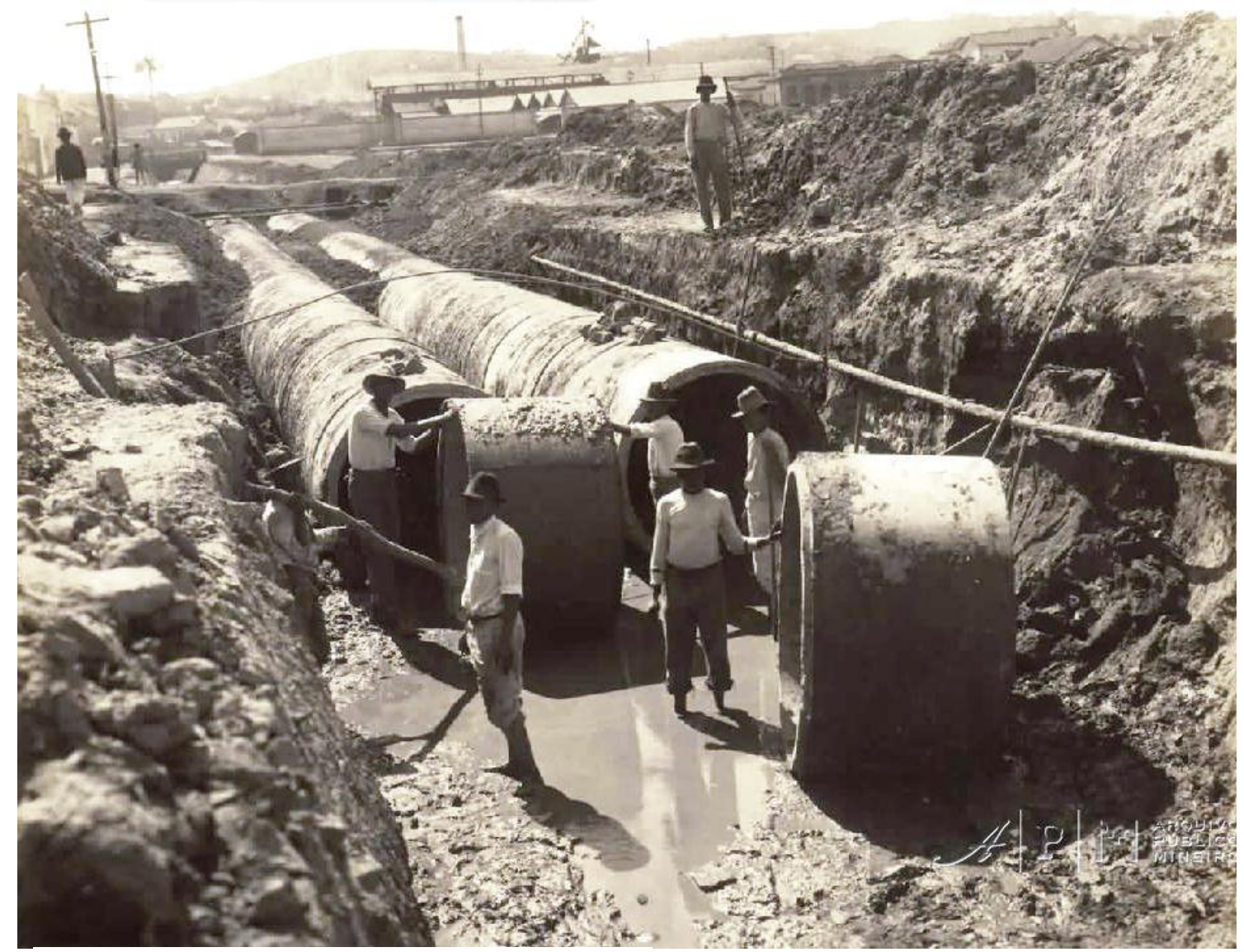

Fonte: Arquivo Público Mineiro, disponível em: http://curraldelrei.blogspot.com/. Acesso em: $10 / 04 / 2020$

8 A enfiteuse (ou aforamento) é um instituto jurídico inaugurado em âmbito nacional pelo Código Civil de 1916. Um modelo de Título/Escritura de Aforamento pode ser verificado em Lima, 2007, p.157. 
Conforme previsto na escritura de aforamento, a propriedade fundiária seria uma possibilidade diante do cumprimento das cláusulas do contrato, não infração de leis municipais e pagamento de 40 foros, após 10 anos de contrato, ou 20 foros, após 30 anos de contrato (LIMA, 2007). Júnia Ferrari Lima (2007), em trabalho sobre a formação do bairro Concórdia, discute o papel do aforamento como possível obstáculo à expansão do mercado imobiliário, pois o bairro se destaca por um processo gentrificação ao longo do século $\mathrm{XX}$ menos agressivo que os bairros vizinhos. Atualmente, o bairro Concórdia é reconhecido no município pela riqueza das manifestações religiosas e culturais de matriz afro-brasileira, práticas que permanecem no território e caracterizam sua população constituída principalmente por mulheres negras. 9

A possibilidade de negociação de terras pelo instituto do aforamento, a partir de 1928, se estende a outras vilas além da Concórdia, territórios negros externos à Zona Urbana: a Vila São Jorge ou Morro das Pedras (região da Gameleira); Vila Conceição ou Pedreira Prado Lopes (região da Lagoinha) e Vila Santo André (região do Carlos Prates). Mesmo diante da ampliação das possibilidades de negociação de terras com operários, loteamentos clandestinos são continuamente criados. E os lotes localizados na Zona Urbana são convenientemente retidos pelo poder público, alimentando um processo de dispersão espacial de núcleos populacionais nos vastos subúrbios carentes de serviços públicos (AGUIAR, 2006; LIMA, 2007). Na luta pela sobrevivência, a população negra passa cada vez mais a se organizar para reivindicar junto ao poder público o acesso às necessidades básicas para a reprodução da vida.

9 Por autodeclaração da cor de pele, conforme pesquisa do IBGE em 2010, o bairro Concórdia possuía população: $56,3 \%$ negra $(32,2 \%$ mulheres negras e $24,0 \%$ homens negros), $43,3 \%$ branca $(25,0 \%$ mulheres brancas e 18,4 homens brancos) e $0,4 \%$ amarela e indígena. 
Figura 4 - Reportagem de 31 de julho de 1934 sobre as necessidades dos bairros

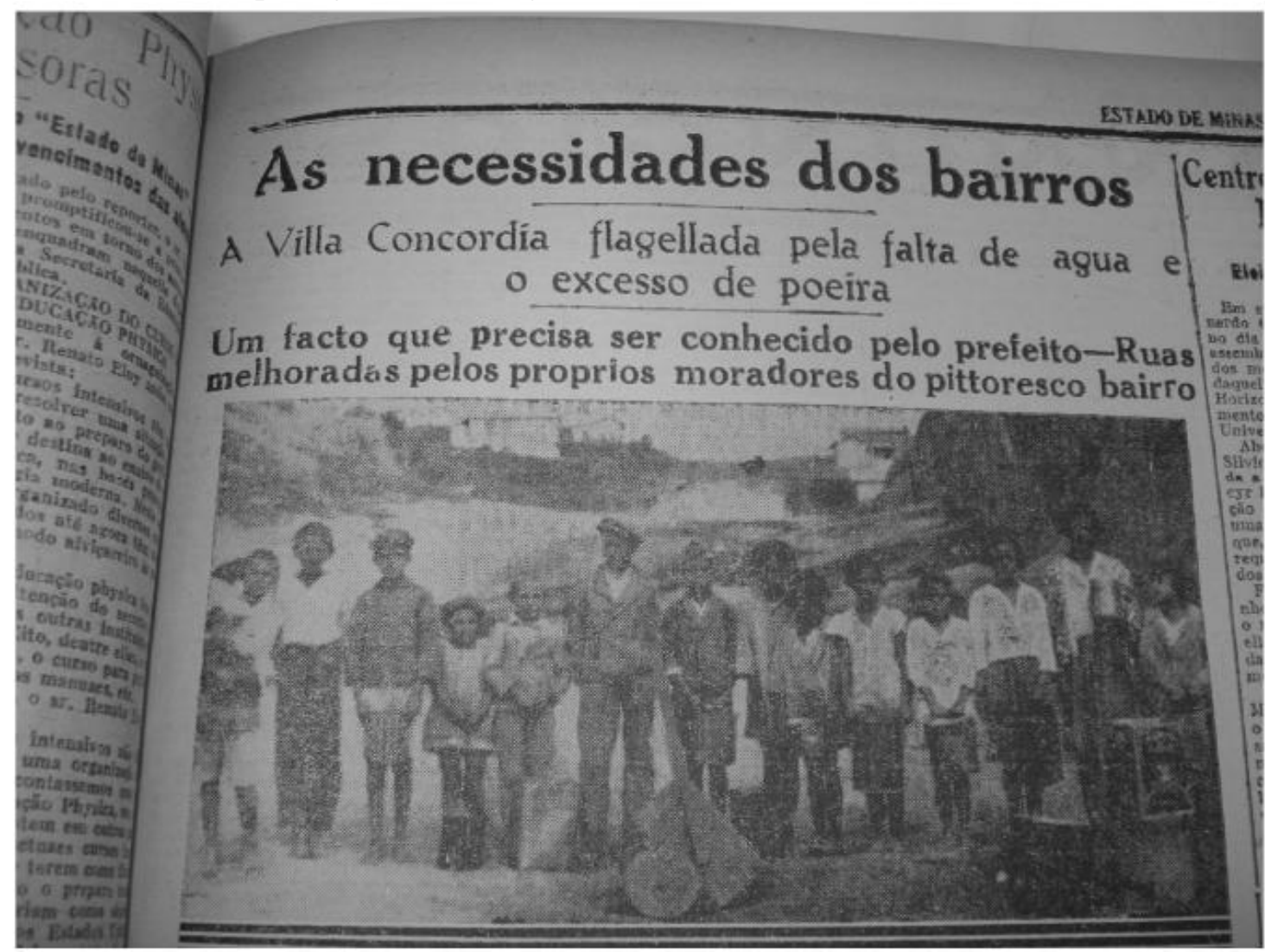

Fonte: Jornal Estado de Minas, 1934 apud Ribeiro, 2008, p. 112

Em 1937, com o golpe de implantação do Estado Novo, a repressão generalizada às formas associativas em Belo Horizonte resultou em um processo de desmobilização de movimentos de reivindicação e o silenciamento, via censura, das formas de mobilização remanescentes (SOMARRIBA, VALADARES E AFONSO, 1984).

Após o ano de 1937, lutas urbanas por condições de sobrevivência continuam a ser travadas pela população proletária organizada em Belo Horizonte e o poder público apresenta respostas aparentemente contraditórias: por um lado incentiva a mobilização e cria formas de atendimento às demandas e por outro reprime organizações populares e promove remoções forçadas. Nos territórios negros, as famílias proletárias organizadas em associações de moradores continuam as lutas urbanas que historicamente incidem na criação de políticas públicas (PEREIRA, 2012).

Segundo Cunha (2019), a história dos bairros negros é pautada pela luta do direito à habitação, inicialmente pelo acesso à terra via loteamentos populares e, posteriormente, o empreendimento de ações pela promoção do ambiente construído; 
essas são consideradas as primeiras reflexões e praticas da luta contra a segregação e a efetivação do território negro (OLIVEIRA, 2016).

\section{PERSPECTIVAS: CONSTRUÇÃO DE POLÍTICAS PÚBLICAS DE REPARAÇÃO}

Apenas na década de 1980, com a ampliação da discussão sobre a posse da terra no âmbito do direito à moradia, é criada a possibilidade de segurança da posse nas favelas de Belo Horizonte por meio da regularização fundiária. ${ }^{10}$ A Lei no 3.995 de 1985 cria o Programa Municipal de Regularização de Favelas (Profavela), consolida as favelas até então existentes no mapa da cidade (como Setor Especial-4) e prevê, além da licitação, a alienação direta das terras às famílias moradoras:

Art. $1^{\circ}$ - Fica criado o Programa Municipal de Regularização de Favelas PROFAVELA

Parágrafo único - O PROFAVELA visa possibilitar a urbanização e regularização jurídica das favelas mencionadas no artigo $1^{\circ}$

Art. $2^{\circ}$ - Fica criado no zoneamento municipal o Setor Especial 4 (SE-4), que compreende as áreas faveladas definidas por esta Lei. (...)

Art. 13 - Os lotes resultantes do parcelamento aprovado na forma desta Lei poderão ser alienados diretamente a seus ocupantes, (...) ou mediante licitação, observadas as normas aplicáveis. (...)

$\S 6^{\circ}$ - Quando se tratar de família não legalmente constituída, a alienação será feita diretamente à mulher, salvo no caso de acordo entre os co-habitantes, hipóteses em que os mesmos passarão a ser co-proprietários do respectivo lote. (...)

Por ser legislação construída a partir de históricas demandas da população organizada, traz a necessidade de atendimento a questões específicas da experiência de gênero, o que é refletido na possibilidade da titulação em nome da mulher no caso de famílias não legalmente instituídas. No ano seguinte à criação do Profavela é criada a Companhia Urbanizadora de Belo Horizonte (Urbel), empresa pública de economia mista que passa a ser responsável por urbanização e regularização em favelas, que envolve tanto titulação quanto remoção de famílias moradoras. Com a criação do

10 A Pastoral de Favelas realizou três congressos de moradores de favelas da Região Metropolitana de Belo Horizonte nos anos de 1980, 1981 e 1982, nos quais o tema dominante foi a posse da terra e sua interferência nas condições de vida. No segundo congresso, realizado de 13 a 17 de maio de 1981, foi decidida a criação de uma Comissão Unitária ligada à Pastoral de Favelas e à União dos Trabalhadores de Periferia (UTP), para prestar ampla assistência jurídica aos moradores de favelas nos seus problemas com moradia, o que se concretizou com a criação da assistência jurídica de advogados de partidos políticos (Somarriba, Valadares e Afonso, 1984). 
Profavela e da Urbel, o poder público reconhece o direito das famílias moradoras de favela à propriedade fundiária, propriedade plena sem menção à titulação coletiva (FERNANDES E PEREIRA, 2010).

A luta dos moradores de favelas pela sobrevivência cria redes e articulações de apoio como o das Comunidades Eclesiais de Base (CEBS), que têm como resultado, na década de 1990, a criação da Política, do Conselho e do Fundo Municipal de Habitação. A Urbel passa a ser responsável por essa política que envolve planejamento urbano e intervenções urbanísticas e produção de moradia específica para população negra.

Na mesma década, em 1998, é criada em Belo Horizonte a Secretaria Municipal para assuntos da Comunidade Negra (SMACON), que inaugura no município, em âmbito institucional, a trajetória de construção da Política Municipal de Promoção da Igualdade Racial em 2010, que cria o Conselho Municipal de Promoção da Igualdade Racial (COMPIR) por meio da Lei Municipal 9.934/2010. Em processo que envolveu a realização de quatro conferências municipais desde a criação da SMACON, foi pactuado no final de 2019 o Plano Municipal de Promoção da Igualdade Racial (PMPIR), com metas específicas de enfrentamento ao racismo institucional. Com o pacto do PMPIR por diversas secretarias municipais é ampliada a possibilidade de articulação entre as políticas de promoção da igualdade racial, urbana e habitacional.

Em 2018, com a revisão da Política Municipal de Habitação, pela primeira vez Povos e Comunidades Tradicionais são incluídos como assentamentos de interesse social pela Resolução LII do Conselho Municipal de Habitação, o que abre a possibilidade da atuação do poder público nos territórios de tradição existentes fora de favelas, e busca reconhecer as especificidades desses territórios, via Política Municipal de Habitação. Ação que percebe-se como contraponto à invisibilidade historicamente dada às especificidades dos territórios negros:

Art. $1^{\circ}$ - Para fins desta Resolução, considera-se:

VIII - Assentamentos de interesse social: assentamentos constituídos predominantemente por famílias de baixa renda, dividindo-se nas seguintes tipologias (...)

g) Povos e Comunidades Tradicionais: assentamentos constituídos por grupos culturalmente diferenciados e que se reconhecem como tais, que possuem formas próprias de organização social, que ocupam e usam territórios e recursos naturais como condição para sua reprodução cultural, social, religiosa, ancestral e econômica, utilizando conhecimentos, inovações e práticas gerados e transmitidos por tradição. 
A luta da população negra pela sobrevivência passa necessariamente pela luta pela moradia que é transfigurada em luta pela propriedade fundiária por exigência das dinâmicas do sistema capitalista. A luta pela propriedade fundiária é carregada de significados que dizem respeito a uma relação com o território que extrapola, e ao mesmo tempo não exclui, a necessidade por ganhos econômicos. O reconhecimento de características específicas dos territórios negros nas políticas públicas pode contribuir no enfrentamento às violações de direitos humanos que ocorrem com a urbanização desses territórios como resultado do racismo estrutural.

No Plano Diretor aprovado em 2019 (Lei No 11.181 de 2019), três comunidades quilombolas reconhecidas pelo Instituto Nacional de Colonização e Reforma Agrária (INCRA) nos anos 2000 e invisibilizadas na política urbana municipal são mapeadas como Áreas Especiais de Interesse Social (AEIS) e Áreas de Diretrizes Especiais (ADE). ${ }^{11}$ Com o reconhecimento como ADE passa a ser prevista regulamentação específica por comunidade quilombola com o objetivo de fortalecer a identidade territorial:

Art. 254 - As ADEs dos Quilombos constituem porções do território municipal sujeitas a políticas específicas de preservação cultural, histórica e ambiental que visem a reforçar a identidade territorial das comunidades quilombolas. (...)

$\S 3^{\circ}$ - São objetivos das ADEs dos Quilombos:

I - reconhecer as especificidades da ocupação de cada quilombo como patrimônio histórico, cultural e simbólico do Município;

II - proteger os espaços e as práticas culturais construídas por essas coletividades, com respeito às suas formas de expressão e aos seus modos de criar, fazer e viver.

III - reconhecer e proteger os territórios quilombolas como parte essencial da identidade dos descendentes negros, bem como elementos necessários à manutenção de um estilo de vida e de formas de sociabilidade próprias;

IV - possibilitar a ocupação e o uso dessas porções territoriais de forma condizente com o modo de vida das respectivas comunidades quilombolas, considerada a condição de uso coletivo da propriedade dos quilombos;

V - garantir a permanência da população residente nos quilombos, em condições de segurança do ponto de vista geológico e geotécnico;

VI - restringir usos que impliquem impactos negativos ou que sejam incompatíveis com as atividades exercidas pelas comunidades.

11 Foram reconhecidas no Plano Diretor de 2019 as Comunidades Quilombolas de Mangueiras, Manzo Ngunzo Kaiango e Luízes. No Plano Diretor de 2010 era reconhecido apenas a Quilombo de Mangueiras. O Plano Diretor foi aprovado após acirrada disputa do empresariado local e dos movimentos sociais. Um dos principais motivadores da disputa foi a implementação do coeficiente de aproveitamento básico associado à Outorga Onerosa do Direito de Construir que representa a possibilidade de avanços por se tratar de instrumento de promoção de políticas de solidariedade. O objetivo da aplicação do instrumento é a distribuição dos ganhos da produção social da cidade para a coletividade. 
Apesar da visibilidade dada à criação das ADES ser parte de uma movimentação antirracista, inversão da histórica invisibilidade, o reconhecimento permanece restrito às comunidades quilombolas que acessaram a política de regularização a partir do auto reconhecimento, o que pressupõe acesso à informação e engajamento político que não se dá da mesma forma em todos os territórios. Nesse sentido, a luta deve continuar.

O histórico de reivindicações da população negra desde o século XIX, que tem nas redes de solidariedade significativas contribuições, vem historicamente corroborando com a busca pela possibilidade de reparações por meio da legislação. Ainda que a simples busca por reparações representem fissuras e não a ruptura com as políticas de morte que viabilizam o funcionamento do sistema de opressão, defende-se a continuidade da disputa por narrativas legislativas como forma de promoção do bem viver.

\section{CONSIDERAÇÕES FINAIS}

A segregação racial em Belo Horizonte foi forjada no âmbito de um projeto moderno para a cidade da república por meio do qual, a despeito da contribuição de diversas etnias na produção da cidade, foram criados núcleos embranquecidos patriarcais elitizados onde deveria permanecer acumulado o capital econômico e político produzido pelo conjunto da sociedade; um ciclo de privilégios operados por mecanismos discriminatórios a serviço da manutenção da hierarquização socioespacial.

Externo à cidade moderna, ou aos núcleos embranquecidos, a vida, a identidade, a cultura, a história e a memória das variadas experiências de sociedade e território produzidas, sobretudo pela população negra, mas não apenas, é reproduzida e transborda colocando em cheque a ideia da modernidade como garantidora do bem viver.

Afinal, as partes solicitam o todo e a modernidade adoece cada vez mais com o seu projeto, suas ausências e praças vazias. Promessas não cumpridas de igualdade dão evidências das falhas de um modelo onde não coube a maioria (GOMES, 2012, p. 147).

Ângela Gomes (2012), ao denunciar o adoecimento da modernidade, convida à reflexão: afinal, como construir uma cidade democrática? E como pensar em 
democracia se parte da população é historicamente desumanizada? Em primeiro lugar, políticas públicas devem ser para a promoção da vida.

Desafio posto, tem-se no retorno ao passado a indicação de possíveis caminhos para os processos de elaboração de políticas públicas: i) incluir representantes de diversas etnias, gêneros e classes organizados em movimentos pela coletividade (as lutas coletivas são fator chave para a constituição de novas dinâmicas de poder) nos processos e instâncias de tomada de decisão, de modo a romper com o predominante ponto de vista patriarcal e colonial realizado a partir dos núcleos embranquecidos; ii) dar visibilidade à diversidade étnico-racial presente nos territórios da cidade, pelo reconhecimento e discussão da existência de histórias, memórias e patrimônios; iii) discutir a segregação étnico-racial no âmbito das políticas públicas, de modo a formar os atores que operacionalizam as políticas; iv) articular as agendas das Políticas Urbana e Habitacional às agendas da Política de Promoção da Igualdade Racial, de modo a construir a convergência de propostas de reparação.

Políticas públicas que se proponham sensíveis às questões estruturais devem considerar em sua formulação as variadas dimensões da experiência social - raça, gênero e classe. E apesar da efetivação das reparações passarem necessariamente pela transgressão da legislação - discurso em disputa -, pela incidência política de atores com distintas experiências diante das dinâmicas estruturais - colonial, patriarcal e capitalista -, pela ação articulada dos movimentos de reivindicação coletiva nos processos de decisão sobre a cidade, é principalmente por meio de um pacto social pela solidariedade que acredita-se ser possível reverter os efeitos das políticas de morte em busca da construção do bem viver.

\section{REFERÊNCIAS BIBLIOGRÁFICAS}

AGUIAR, Tito Flávio Rodrigues de. Vastos Subúrbios da Nova Capital: formação do espaço urbano na primeira periferia de Belo Horizonte. 2006. 443 p. Tese (Doutorado em História) Faculdade de Filosofia e Ciências Humanas, Universidade Federal de Minas Gerais, Belo Horizonte, 2006.

BELO HORIZONTE. Lei $n^{\circ} 33$, de 11 de fevereiro de 1909. Desloca área operária para a oitava secção urbana.

. Lei $n^{\circ}$ 309, de 28 de outubro de 1926. Contém disposições sobre a venda de lotes.

Lei $n^{\circ} 335$, de 4 de abril de 1928. Concede lotes por emphyteuse a operários.

Lei $n^{o} 3.995$, de 16 de janeiro de 1985. Introduz dispositivos na Lei 3.532, de 06 de

janeiro de 1983 - Cria o Programa Municipal de Regularização de Favelas - PROFAVELA - e dá outras providências. 
Lei $n^{o}$ 9.934, de 21 de junho de 2010. Dispõe sobre a Política Municipal de

Promoção da Igualdade Racial, cria o Conselho Municipal de Promoção da Igualdade Racial e dá outras providências.

Lei $n^{\circ} 11.181$, de 8 de agosto de 2019. Aprova o Plano Diretor do Município de Belo

Horizonte e dá outras providências.

BOTELHO, Tarcísio Rodrigues. A migração para Belo Horizonte na primeira metade do século XX. Cadernos de História, Belo Horizonte, v. 9, n. 12, p. 11-33, $2^{\circ}$ sem. 2007.

BRASIL. Lei $n^{\circ} 2.040$ de 28 de setembro de 1871. Declara de condição livre os filhos de mulher escrava que nascerem desde a data desta lei, libertos os escravos da Nação e outros, e providencia sobre a criação e tratamento daquelles filhos menores e sobre a libertação annual de escravos.

Lei $n^{\circ} 601$ de 18 de setembro de 1850. Dispõe sobre as terras devolutas do Império.

CONSELHO MUNICIPAL DE HABITAÇÃO DE BELO HORIZONTE. Resolução LII. Dispõe sobre a estrutura geral da Política Municipal de Habitação para Belo Horizonte, 2018.

COSTA, Emília Viotti da. Da Monarquia à República: momentos decisivos. 9 ed. São Paulo: Editora UNESP, 2010.

CRENSHAW, Kimberlé. Mapping the Margins: Intersectionality, Identity Politics, and Violence Against Women of Color. Stanford Law Review, Vol. 43 (1991): pp. 1241-1299.

CUNHA JUNIOR, Henrique. Bairros Negros: A forma urbana das populações negras no Brasil. Revista da Associação Brasileira de Pesquisadores/as Negros/as (ABPN), v.11, n. Edição Especial, p.65-86, maio 2019. ISSN 2177-2770. Disponível em: <https://abpnrevista.org.br/index.php/site/article/view/683>. Acesso em: 30 março, 2020.

FERNANDES, Edésio; PEREIRA, Helena Dolabela. Legalização das favelas: qual é o problema de Belo Horizonte? Planejamento e Políticas públicas, ${ }^{\circ} 34$ (2010): Planejamento e Políticas Públicas - PPP.

GARCIA, Antônia dos Santos. Desigualdades raciais e segregação urbana em antigas capitais: Salvador cidade D'Oxum e Rio de Janeiro, cidade de Ogum / Rio de Janeiro: Garamond, 2009. $14 \times 21 \mathrm{~cm} ; 544 \mathrm{p}$.

GOMES, Ângela Maria da Silva. Etnobotânica e territorialidades negras urbanas da grande Belo Horizonte: terreiros e quintais. In: SANTOS, Renato Emerson dos (Org.). Questões Urbanas e Racismo. Petrópolis, RJ; Brasília, DF: DP et alii; ABPN, 2012 - p. 276-309. (Negras e Negros: Pesquisas e Debates).

GUIMARÃES, Berenice. Cafuas, Barracos e Barracões: Belo Horizonte, cidade planejada 1894-1945. 1991. Tese (Doutorado em Sociologia). Instituto Universitário de Pesquisas do Rio de Janeiro - IUPERJ. Rio de Janeiro/RJ, 1991.

GUIMARÃES, Berenice. Favelas em Belo Horizonte: tendências e desafios. Análise \& Conjuntura, Belo Horizonte, v.7, n.2 e 3, maio/dez. 1992.

JACCOUD, Luciana. Capítulo 2 - Racismo e república: o debate sobre o branqueamento e a discriminação racial no brasil. In: THEODORO, Mário; JACCOUD, Luciana; OSÓRIO, Rafael; SOARES, Sergei (org.). As políticas públicas e a desigualdade racial no Brasil: 120 anos após a abolição / - Brasília: Ipea, 2008. p.45-64. 
LIMA, Junia Maria Ferrari de. Bairro Concórdia em Belo Horizonte: entrave ou oportunidade à cidadenegócio? Belo Horizonte, Escola de Arquitetura da Universidade Federal de Minas Gerais, 2009. Dissertação (mestrado).

MINAS GERAIS. Lei Adicional $n^{\circ} 3$ de 17 de dezembro de 1893. Fixa o lugar em que deve ser construída a capital do Estado e dá outras providências.

Decreto $n^{o} 1.516$ de 2 de maio de 1902. Regula a concessão de terrenos à indústrias, associações e a venda a particulares.

MUNANGA, Kabengele. Negritude: Usos e Sentidos, 2ª edição. São Paulo: Ática, 1986.

OLIVEIRA, Reinaldo José de. Territorialidade Negra e Segregação Racial na cidade de São Paulo: a luta por cidadania no século XX. São Paulo, Editora Alameda, 2016.

OLIVEIRA, Reinaldo José (Org). A Cidade e o negro no Brasil: cidadania e território. 2. São Paulo: Alameda, 2013. 268 p.

OLIVEIRA, Reinaldo José de. SOUZA OLIVEIRA, Regina Marques de. Origens da segregação racial no Brasil, Amérique Latine Histoire et Mémoire. Les Cahiers ALHIM [En línea], 29 | 2015. Disponível em: http://alhim.revues.org/5191. Acesso em 17/07/2017.

PEREIRA, Josemeire Alves. O tombamento do "Casarão da Barragem" e as representações da favela em Belo Horizonte. Dissertação (Mestrado em História), Universidade Estadual de Campinas, Campinas, SP, 2012.

PEREIRA, Josemeire Alves. Histórias familiares, trajetórias e experiências de liberdade de afrodescendentes em Belo Horizonte, MG. ANPUH. XXVIII Simpósio Nacional de História, $2015 b$.

RIBEIRO, Andréia. Representações e práticas cotidianas de um bairro Belorizontino: o Concórdia. Dissertação (Mestrado em Ciências Sociais), Pontifícia Universidade Católica de Minas Gerais, Belo Horizonte, MG, 2008.

RIBEIRO, Luiz Cesar de Queiroz. Sobre o IBEU. Disponível em: https://ibeu.observatoriodasmetropoles.net.br/sobre1/. Acessado em: 25/02/2020

ROLNIK, Raquel. A cidade e a lei: legislação, política urbana e território na cidade de São Paulo. São Paulo: Studio Nobel: Fapesp, 1997(Coleção cidade aberta).

SANTOS, Milton. Técnica, espaço, tempo: globalização e meio técnico científico informacional. $4^{a}$ edição, São Paulo: Editora Hucitec, 1998.

SILVA, Lisandra Mara. Horizonte segregado: os papéis do ordenamento técnico na produção da cidade. Arquitetas Negras, v. 1, $1^{\text {a }}$ edição, 2019, p. 44-64.

SILVA, Lisandra Mara. Propriedades, negritude e moradia na produção da segregação racial da cidade: cenário Belo Horizonte. Dissertação (Mestrado em Arquitetura e Urbanismo), Universidade Federal de Minas Gerais, Belo Horizonte, MG, 2018.

SILVA, Lisandra Mara; PEREIRA, Josemeire Alves. O estigma do invasor na produção do espaço urbano - O caso de Belo Horizonte. In: LIBÂNIO, Clarice de Assis e PEREIRA, Josemeire Alves (org.) - Periferias em rede: experiências e perspectivas. Belo Horizonte: Favela é Isso Aí, 2018. 288p.: il. p\&b. (Prosa e Poesia no Morro). 
SILVA, Margarete Maria de Araújo. Água em meio urbano, favelas nas cabeceiras. Tese (Doutorado em Arquitetura e Urbanismo), Universidade Federal de Minas Gerais, Belo Horizonte, MG, 2013.

SOMARRIBA, Maria das Mercês Gomes; VALADARES, Maria Gezica; AFONSO, Mariza Rezende. Lutas Urbanas em Belo Horizonte. Belo Horizonte: Vozes Petrópolis em co-edição com Fundação João Pinheiro, 1984. 130p.

VAINER, Carlos Bernardo. Do corpo marcado ao território demarcado: uma leitura da transição para o trabalho livre como ponto de partida para uma história da mobilidade do trabalho no Brasil. Cadernos de migração: São Paulo, n. 7, 2000, p.59-88.

Recebido em: 22/09/2020

Aceito em: 30/10/2020 